\title{
Crude extracts of Sesamum Indicum roots used as anthraquinone source effect on pulping with sodium hydroxide of Sudanese bagasse
}

\author{
Suhair Kamalaldeen Shomeina', Osman Taha Elzaki', Sakina Yagi ${ }^{2}$, Salaheldin Dafaalla Mohieldin \\ and Tarig Osman Khider ${ }^{3^{*}}$ (D)
}

\begin{abstract}
The objectives: The work was carried out for extraction of natural anthrasesamones from roots of Sesamum Indicum using different organic solvents and utilization of extracts as catalyst in pulping with sodium hydroxide for a by-product of sugar industry (Sudanese bagasse).

Results: Sesamum Indicum roots when extracted with ethanol, it gave the highest extracts yield \% (0.964), followed by ethyl acetate, chloroform, dichloromethane and petroleum ether extracts. The chemical pulping of Bagasse was done by using of sodium hydroxide, sodium hydroxide with anthraquinone, and sodium hydroxide with extract instead of anthraquinone keeping constant conditions at temperature $160^{\circ} \mathrm{C}$ and applied sodium oxide $10.9 \%$ and time was 120 min, gave promising screened yield between 49.84 and 53.68\%, bleachable kappa number between 15.57 and 8.26 for sodium hydroxide only and cooking with sodium hydroxide with anthraquinone. Cooking with sodium hydroxide of bagasse with anthrasesamones gave good pulping yields and kappa number.
\end{abstract}

Keywords: Sesamum Indicum, Anthraquinone (AQ), Anthrasesamones, Cooking with sodium hydroxide, Bagasse, Pulp yield, Kappa number

\section{Introduction}

Sesame (Sesamum Indicum L.), a member of the family Pedaliaceae, is widely grown in Sudan under rain fed conditions. The average seed yield in Sudan is about $350 \mathrm{~kg} /$ ha. It is one of the most important cash crops. Sudan (38.2\%), India, Myanmar and China are the most important sesame producers with $68 \%$ of the world production [1] According to Encyclopedia Britannica "sesame, called Benne, it is an erect, annual plant (Fig. 1) [2].

Sesame (Sesamum Indicum L.) is known as simsim (Sudanese), till (Hindi), hu ma (Chinese), sesame (French), goma (Japanese), gergelim (Portuguese) and ajonjolí (Spanish). It is also considered to be a beneficial for food and health [2, 3]. $100 \mathrm{~g}$ of sesame provides $100 \%$

\footnotetext{
*Correspondence: tarigosmankhider@gmail.com

${ }^{3}$ College of Applied and Industrial Sciences, University of Bahri Sudan, P.O. Box 1606, Khartoum, Sudan

Full list of author information is available at the end of the article
}

of the recommended daily allowance (RDA) for manganese and potassium, 57-65\% of the RDA of phosphorus and iron, and $13-35 \%$ for zinc, calcium (helps to prevent colon cancer and osteoporosis) and copper (reducing pain and swelling of rheumatoid arthritis) are recommended daily intake is 25 to $50 \mathrm{~g}[4,5]$.

Sesame seeds are used in baking and making candy while its oil, in addition to cooking, is used in the manufacture of soaps, paints, perfumes, cosmetics, and hair oils. Sesame oil has many pharmaceutical activities like antioxidant, antibacterial, cardio tonic, and anti-diabetic [6], hypocholesterolemic [7] antitumor [8, 9], antiulcer [10], and anti-inflammatory [11]. These uses are due to its antioxidant properties which accounted for by the presence of secondary metabolites. Secondary metabolites purified from seeds and roots of sesame include sesamol, sesaminol, sesamin, sesamolin, naphthoquinone hydroxysesamone and 2,3-epoxysesamone and anthrasesamones A-F. Some of these chemicals are reported to 


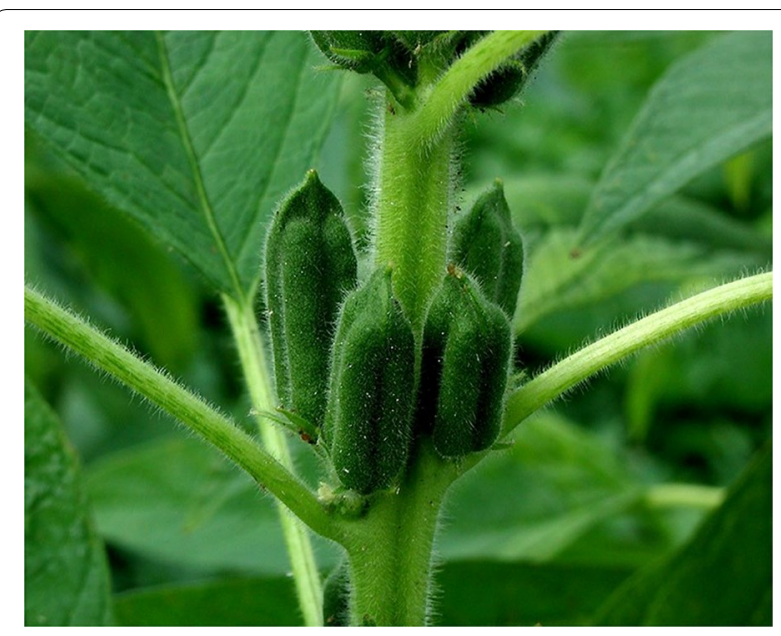

Fig. 1 General morphology of Sesamum Indicum http://commo ns.wikimedia.org/wiki/Main_Page

have antimicrobial properties $[4,12,13]$. In Nigeria, the leaves and roots of sesame plant are used for treating migraine, hypertension, ulcer, constipation, chicken pox and pile [12, 14]. The roots of $S$. indicum produced five unusual anthraquinones (Anthrasesamones A, B, C, D and $\mathrm{E}$ ) having $\mathrm{C} 6$ side chains at $\mathrm{C}-2$ in the anthraquinone ring [15]. In particular, anthrasesamone $C(6)$ is a chlorine-containing anthraquinone, which is a rare metabolite in higher plants [3, 4].

Anthraquinones $(\mathrm{AQ})$ are natural pigments that are found in some plants, fungi, lichens and some insects [16, 17]. Anthraquinones are widely applied in medicine, food and dye industry [18]. Anthraquinone is an important catalyst that is used as an additive in chemical alkaline wood pulping for its effectiveness in accelerating delignification, lowering carbohydrate degradation and improve pulp yield [16, 19, 20]. Anthraquinone will reduce the active alkali consumption, increase the degree of delignification, and increase the yield, the addition of about $0.1 \%$ anthraquinone on wood base results in a $1-3 \%$ increase in pulp yield [19].

The mechanism of anthraquinone functions in a redox reaction. anthraquinone cycles between its insoluble oxidized form and its soluble reduced form. First, anthraquinone reacts with the reducing group of a carbohydrate to be more stable against alkaline peeling reactions and producing the reduced soluble form of anthrahydroquinone. Then, the anthrahydroquinone (AHQ) reacts with the quinone methide segment of the lignin polymer increasing the rate of delignification. The anthrahydroquinone (AHQ) is also converted back to anthraquinone (AQ) at the same time and finishes a cycle reaction [21]. Utilization of anthraquinone (AQ) in sodium hydroxide cooking of bagasse, it accelerates the delignification to produce higher yields, lower Kappa numbers better mechanical properties of pulps similar to Kraft pulp grades [22, 23]. Sudan is rich country with pulp and papermaking raw materials that include non-woody plants, agricultural residue, recycled papers, as well as hard wood species [24].

The present work aiming to extract of natural anthrasesamones from roots of Sesamum Indicum applied with different organic solvents and utilize it as anthraquinone (AQ) catalyst in cooking with sodium hydroxide of Sudanese bagasse for production of pulp paper making.

\section{Main text \\ Methods}

About $20 \mathrm{~kg}$ of bagasse were transported from Sugarcane Factory (Additional file 1: Figures S1, S4, S5) (White Nile State-Sudan) to National Centre of research, Cellulose Chemistry and Technology Research Unit in 2014 by bus according to Technical Association of Pulp and Paper Industry standards TAPPI [25]. Bagasse was prepared accordingly by drying in air followed by screening to remove the dirt and dust by dry depithing and screened by standard sieve. Matured Sesamum indicum (Simsim) roots were collected from White Nile state Roots were ground in a standard star mill with a standard sieve and closed till used. The plant species were authenticated by Dr. Hayder Abd-Algadeer Assistant Professor in Herbarium of Medicinal and Aromatic plants Institute, National Centre for Research.

Ethanol, ethyl acetate, chloroform, petroleum ether and dichloromethane were selected to extract the chemical components from Sesamum indicum roots (Additional file 1: Figure S2) according previous studies [18, 26-29]. The other chemicals used were potassium permanganate, potassium iodide, sodium thiosulphate, sodium hydroxide pellets purified, potassium hydroxide and starch soluble from Chemical Limited Poole England. Sulphuric acid 98\% and ammonia solution from Romil Pure Chemistry. Anthraquinone from Prolabo. The chemicals were used in pulping process, determination of kappa number and identification of anthraquinones.

The presence of the anthraquinones in the Sesamum indicum roots was tested by using two grams of milled roots followed by boiling with $0.5 \mathrm{~N}$ potassium hydroxide $\mathrm{KOH}$, and addition of $10 \mathrm{ml}$ of chloroform; then shaking and the filtration was done. Addition of $3 \mathrm{ml}$ ammonia with $10 \%$ concentration was done, the red pinkish color in ammonia was sign presence of anthraquinones according to Neeta [4].

The extraction with ethanol, ethyl acetate, chloroform, petroleum ether 60-80 and dichloromethane was done separately for $30 \mathrm{gm}$ of Sesamum indicum roots using a 
Soxhlet extraction unit, the crude extracts were evaporated to dryness on rotator evaporator.

Cooking with sodium hydroxide, sodium hydroxide with anthraquinone (AQ) and sodium hydroxide with crude extract containing anthraquinone were applied in 7-litre rotary electrically heated digester. Bagasse was cooked according to following conditions, Active alkali as sodium oxide $\mathrm{Na}_{2} \mathrm{O}$ was $10.9 \%$, Anthraquinone (AQ) concentration $0.1 \%$, liquor to bagasse ratio $5: 1$, with maximum temperature $160{ }^{\circ} \mathrm{C}$, time to maximum temperature $120 \mathrm{~min}$ and time at maximum temperature $90 \mathrm{~min}$. Pulping liquors were added directly at the start of cooking. Determination of moisture content of each pulp was done, the total yield (combination of screened yield and rejects) were calculated. Kappa number (degree of delignification) was carried out according to Technical Association of Pulp and Paper Industry standards (TAPPI) T236 om-99.

\section{Results}

All extractives under investigation gave positive results thus extract with ethanol, ethyl acetate, chloroform, dichloromethane and petroleum ether 60-80 gave $0.964 \%, 0.876 \%, 0.664 \%, 0.605 \%$ and $0.264 \%$, respectively and this agreed with Furumoto and his research work group [15].

Bagasse was chosen due to the fact that it was Industrial agricultural waste and mostly utilized for energy supply in sugar and ethanol mills as well as easy to be cooked for bleachable kappa number. It was cooked with sodium hydroxide and sodium hydroxide with AQ cooking with yields presented in Table 1 depending on Karar [30]. Application of sodium hydroxide only at maximum temperature $160^{\circ} \mathrm{C}$ for $2 \mathrm{~h}$ and active alkali from $10.9 \%$ as $\mathrm{Na}_{2} \mathrm{O}$ gave bleachable Kappa number and screened yield $49.8 \%$. Anthraquinone (AQ) is a powerful redox-catalyst in alkaline pulping especially when non-woody raw material is cooked [31,32], with

Table 1 Pulping properties of sodium hydroxide and sodium hydroxide with anthraquinone of bagasse

\begin{tabular}{lll}
\hline Conditions & Soda & Soda AQ \\
\hline Active alkali as $\mathrm{Na}_{2} \mathrm{O} \%$ & 10.9 & 10.9 \\
Liquor to bagasse ratio & 5 & 5 \\
Maximum temperature, ${ }^{\circ} \mathrm{C}$ & 160 & 160 \\
Time at maximum temperature, min & 120 & 120 \\
Screened yield\% $^{20}$ & 49.8 & 53.7 \\
Reject\% & 0.3 & 0.4 \\
Total yield\% & 50.1 & 54.1 \\
Kappa No. & 15.8 & 8.3 \\
\hline
\end{tabular}

addition of $0.1 \mathrm{AQ}$ at same cooking conditions higher degree of delignification (kappa number 8.26) was attained associated with increase in screened yield (53.7\%). It well known that the addition of AQ accelerated the delignification and preserved the carbohydrates [33-37].

The results achieved by using Sesamum Indicum roots crude extractives as $\mathrm{AQ}$ source applying to cook bagasse with soda according to the reference cooks, showed that, the most promising findings were achieved by pulping with dichloromethane extracts (Additional file 1: Figure S3), which obtained highest screened yield (50.5\%), satisfactory kappa number (19.4) and negligible rejects (1.64\%) and this agreed with Furumoto [15].

This followed by petroleum ether extracts with screened yield (49.8\%), and kappa number (22.1). Chloroform extractives obtained screened yield (45.4\%) and admitted kappa number (24.9). Figure 2 and (Additional file 1: Table S1) showed that Ethyl acetate and ethanol crude extracts when used as substitute of AQ catalyst attained lowest screened yield $(44.8 \%$ and $43.5 \%)$, respectively, with suitable kappa number (25.1 and 27.5), respectively. Also it could be noticed that the rejects ranged between $(1.6 \%$ and $2.7 \%)$ with the exception of chloroform extract (4.6\%) and as observed previously the screened yields increased and kappa numbers decreased according to the polarity of the solvents used. It could be noticed that Sesamum Indicum roots extracts have produced acceptable to satisfactory yields \% and this due to the structure of the five anthrasesmonones that was found in the roots of Sesamum Indicum as mentioned by [3, 4] All of their structures have alkene chain in position 2 or 3 . Adding the crude extracts of roots of Sesamum Indicum as AQ catalyst, this alkene chain may caused steric hindrance and prevents the reaction(to some extend) between the rest of AQ and the aryl ether bond or alkyl ether bond of side chain of lignin. This explicated the limited range of increasing screened yield by use the five organic solvent to extract the AQ. This improves the selectivity with respect to lignin removal without significant carbohydrates degradation.

Sugar industry is a strategic industry which high impact factor in national income White Nile factory is one of sugar factories in Sudan. Bagasse is fibrous matter that remains after sugar cane, for each ten tons of sugar cane crushed produced nearly three tones of wet bagasse, part of it used as biofuel. Unused bagasse was available on site in all of sugar factories causes' environmental pollution and health complications (Additional file 1: Figure S6). Rational use of bagasse as source of pulp production instead of being an environmental pollutant. 


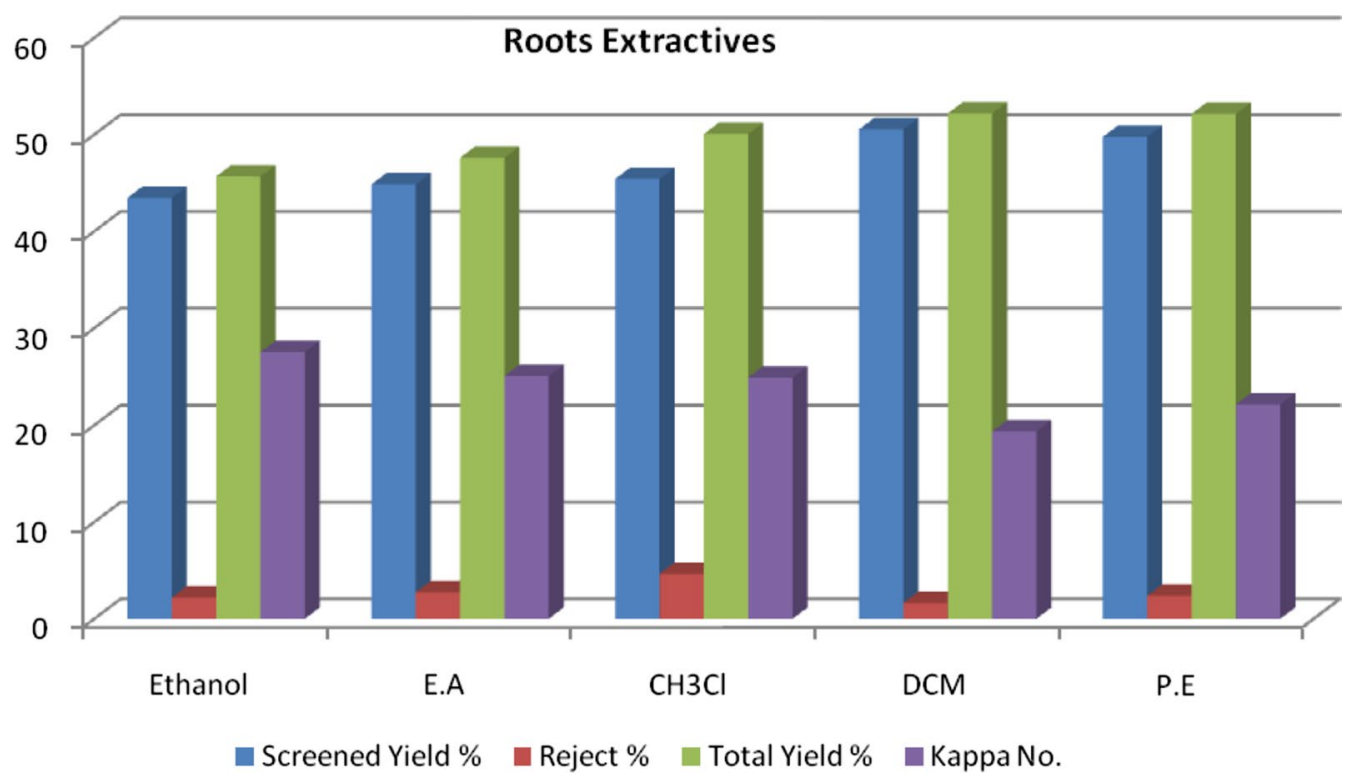

Fig. 2 Pulping results for Sesamum Indicum roots extract with different organic solvents as substitute of anthraquinone catalyst. Where: E.A., Ethyl acetate; $\mathrm{CH}_{3} \mathrm{Cl}$, chloroform; DCM, Dichloromethane; P.E., Petroleum ether $60-80$

\section{Limitations}

The crude extracts of dichloromethane from Sesamum Indicum roots applied as Anthraquinone in pulping of bagasse indicated the suitability of this extract in chemical pulping. Although the results of pulping presented higher kappa number and reduced screened yield when compared with synthesized anthraquinone.

The purification of the crude extracts of the five solvents under study could provide suitable anthrasesamones as substitute of anthraquinones. The sodium hydroxide cooking of non woody plants, and agricultural residues with anthrasesamones improved the pulping yields and kappa number.

The study of the bagasse as by product in sugar industry, its utilization and its effect on environment and health should be done.

Application of purified extract with well-known chemical structure is highly needed. The analysis of extracts by spectral such as High Performance Liquid Chromatography, Ultraviolet-visible spectroscopy or ultravioletvisible spectrophotometry, Fourier-transform infrared spectroscopy Nuclear magnetic resonance and electrospray ionization mass spectrometry is highly needed.

\section{Additional file}

Additional file 1: Figure S1. White Nile Sugar Factory, White Nile State, Centre of Sudan (Source of Bagasse raw materials). Figure S2. Ethanol, ethyl acetate, chloroform, dichloromethane and petroleum ether of Roots of S. indicum. Figure S3. Pulp with dichloromethane extracts and sodium hydroxide of bagasse. Figure S4. Production of Sugar in White Nile Factory, White Nile state, Centre of Sudan. Figure S5. Amount of Bagasse as (byproduct unused bagasse) in White Nile Factory, White Nile State, and Centre of Sudan. Figure S6. Remains of Bagasse burned by sun rays and ash, causes environmental pollution and health complications. Table S1. Pulping properties for $S$. indicum roots extract with different organic solvents as anthraquinone catalyst.

\section{Abbreviations}

AQ: anthraquinone; RDA: recommended daily allowance; $A H Q$ : anthrahydroquinone; $\mathrm{KOH}$ : potassium hydroxide; $\mathrm{Na}_{2} \mathrm{O}$ : sodium oxide; TAPPI: Technical Association of Pulp and Paper Industry.

\section{Authors' contributions}

SKS and TOK were carried out, sodium hydroxide with and without extracts, sodium hydroxide with anthraquinone pulping and revised the draft manuscript. OTE did pulp evaluation and analysis of Kappa number, review the draft manuscript, SDM and SY were collected the samples and prepared them and did phytochemical screening and revised the draft manuscript. SKS and TOK designed the study and wrote the draft manuscript. All authors read and approved the final manuscript.

\section{Author details}

${ }^{1}$ Cellulose Chemistry and Technology Research Unit, National Centre of Research, Khartoum, Sudan. ${ }^{2}$ Faculty of Science, Botany Department, University of Khartoum, Khartoum, Sudan. ${ }^{3}$ College of Applied and Industrial Sciences, University of Bahri Sudan, P.O. Box 1606, Khartoum, Sudan.

\section{Acknowledgements}

Authors grateful for the Cellulose Chemistry and Technology Research UnitNational Centre for Research (NCR)-Khartoum, Sudan for using of research facilities. Thanks to Dr. Hayder Abd-Algadeer Medicinal and Aromatic plants Institute (MAPTMRI) for identification of plant species.

\section{Competing interests}

Not applicable. 


\section{Availability of data and materials}

We have already included most of data in the manuscript, the lab and data, some data not included in the manuscript attached as Additional file.

\section{Consent for publication}

Not applicable.

Ethics approval and consent to participate

Not applicable.

\section{Funding}

Not applicable.

\section{Publisher's Note}

Springer Nature remains neutral with regard to jurisdictional claims in published maps and institutional affiliations.

Received: 4 December 2018 Accepted: 11 January 2019

Published online: 15 January 2019

\section{References}

1. Abdellatef E, Sirelkhatem R, Mohamed Ahmed MM, Radwan KH, Khalafalla MM. Study of genetic diversity in Sudanese sesame (Sesamum indicum L.) germplasm using random amplified polymorphic DNA (RAPD) markers. Afr J Biotechnol. 2008;7(24):4423-7.

2. Vijay R, Sharmila KP, Mahesh PB, Suchetha KN, Pushpalatha KC. Evaluation of phytochemical constituents and fatty acid content in Sesamum indicum L. J Pharm Chem Bio Sci. 2015;3(1):84-90.

3. Chakraborthy GS, Sharma G, Kaushik KN. Sesamum Indicum: a review. J Herb Med Toxicol. 2008;2(2):15-9.

4. Neeta MP, Mukta N, Bilwa K. Comparative qualitative phytochemical analysis of Sesamum indicum L. Int J Curr Microbiol App Sci. 2015;2:172-81.

5. Asghar A, Majeed MN, Akhtar MN. A review on the utilization of sesame as functional food. Am J Food Nutr. 2014;4(1):21-34.

6. Amutha K, Godavari A. In-vitro-antidiabetic activity of N-butanol extract of Sesamum indicum. Asian J Pharm Clin Res. 2016;9(4):60-2.

7. Pusadkar PP, Kokiladevi E, Bonde SV, Mohite NR. Sesame (Sesamum indicum L.) importance and its high quality seed oil: a review. Trends Biosci. 2015;8(15):3900-6.

8. Sahin S, Elhussein EAA. Assessment of sesame (Sesamum indicum L) cake as a source of high-added value substances: from waste to health. Phytochem Rev. 2018:1:1. https://doi.org/10.1007/s11101-018-9554-4.

9. Kumar A, Pal A, Khanum F, Bawa AS. Nutritional, medicinal and industrial uses of sesame (Sesamum indicum L.) seeds-an overview. Agriculturae Conspectus Scientifi cus. 2010;75(4):159-68.

10. Hussain I, Hazarikaand M, Das A. Anti-ulcer activity of ethanolic extract of Sesamum indicum seed on indomethacin-induced ulcer model and its antioxidant property in gastro-protection. Res Rev J Pharmacol. 2015:5(2):18-25.

11. Rangkadilok N, Pholphana N, Mahidol C, Wongyai W, Saengsooksree K, Nookabkaew S, Satayavivad J. Variation of sesamin, sesamolin and tocopherols in sesame (Sesamum indicum L.) seeds and oil products in Thailand. Food Chem. 2010;122(3):724-30.

12. Alege $\mathrm{GO}$, Akinyele $\mathrm{BO}$, Osekita OS. Phytochemical studies and genetic diversity in sesame (Sesamum indicum L.). In: Proceedings of the world congress on engineering London. 2014.

13. Syed RN, Laurentin H, Splivallo R, Karlovsky P. Antifungal properties of extracts of sesame (Sesamum indicum). Int J Agric Biol. 2015;17(3):575-81.

14. Ajayi IA, Adeshina Al. Chemical analysis and toxicological assessment of Sesamum indicum seed cake on albino rats. J Environ Sci Toxicol Food Technol. 2014;8(7):v60-6.
15. Furumoto T, Takeuchi A, Fukui $H$. Anthrasesamones $D$ and $E$ from Sesamum indicum Roots. Biosci Biotechnol Biochem. 2006;70(7):1784-5.

16. HSDB Hazardous Substance Data Bank Anthraquinone. (CAS No. 84-65-1), IPCS-CEC International chemical safety cards on Anthraquinone and NTP technical report on the toxicology and carcinogenesis studies of anthraquinone (CAS No. 84-65-1) Natl Toxicol Program Tech. 2010;494:1-358.

17. Dave H, Ledwani L. A Review on anthraquinones isolated from cassia species and their applications. Indian J Nat Prod Resour. 2012;3(3):291-319.

18. Mohanlall V, Steenkamp P, Odhav B. Isolation and characterization of anthraquinone derivatives from Ceratotheca triloba (Bernh.) Hook. f. J Med Plants Res. 2011;5(14):3132-41.

19. Biermann CJ. Handbook of pulping and papermaking. San Diego: Elsevier Science \& Technology Books; 1996. p. 745.

20. Butterworth BE, Mathre OB, Ballinger KE, Orn. Contamination is a frequent confounding factor in toxicology studies with anthraquinone and related compounds. Int J Toxicol. 2004;23(5):335-44.

21. Elzakia OT, Otuk S, Khider TO. Sulfur-free pulping Of Crateva AdansoniI from Sudan. J For Prod Ind. 2012;1(1):23-6.

22. Khristova P, Kordsachia O, Patt R, Karar I, Khider T. Environmentally friendly pulping and bleaching of bagasse. Ind Crops Prod. 2006;23(2):131-9.

23. Lois-Correa JA. Depithers for efficient preparation of sugar cane bagasse fibers in pulp and paper industry. Ingeniería Investigación y Tecnología. 2012;4(4):417-24

24. Elzaki OT, Khider TO, Omer SH, Shomeina SK. Environment friendly alkaline pulping of Albizia lebbeck from Sudan. Nat Sci. 2012;10(4):76-82.

25. TAPPI. TAPPI test methods. Atlanta: TAPPI Press; 2002.

26. Shotipruk A, Kiatsongserm J, Pavasant P, Goto M, Sasaki M. Pressurized Hot water extraction of anthraquinones from the roots of Morinda citrifolia. Biotechnol Prog. 2004:20:1872-5.

27. Owoyale JA, Olatunji GA, Oguntoye SO. Antifungal and antibacterial activities of an alcoholic extract of Senna alata leaves. J Appl Sci Environ Mange. 2005;9(3):105-7.

28. Ayo RG, Amupitan JO, Zhao Y. Cytotoxicity and antimicrobial studies of 1,6,8-trihydroxy-3-methyl-anthraquinone (emodin) isolated from the leaves of Cassia nigricans. Afr J Biotechnol. 2007;6(11):1276-9.

29. Oliveira M, De C, Negri G, Salatino A, Braga MR. Detection of anthraquinones and identification of 1,4-naphthohydroquinone in cell suspension cultures of Rudgea jasminoides (Cham.) (Rubiaceae). Müll Arg Revista Brasil Bot. 2007;30(1):167-72.

30. Karar IG. Environmentally friendly pulping and bleaching of bamboos and bagasse from Sudan, Ph.D. thesis. University of Khartoum, Department of Forest Product and Industries Faculty of Forestry. 2004.

31. Omer SH, Khider TO, Elzaki OT, Mohieldin SD, Shomeina SK. Application of soda-AQ pulping to agricultural waste (Okra Stalks) from Sudan. BMC Chem Eng (in press).

32. Elzaki OT, Khider TO, Omer SH, Mohieldin SD, Shomeina SK. Suitability of Sudanese pearl millet stalks (Pennisetum glaucum (L.) for alkaline pulping with additives. Songklanakarin J Sci Technol (in press).

33. Khristova $\mathrm{P}$, Kordsachia $\mathrm{O}$, Khider T. Alkaline pulping with additives of date palm rachis and leaves from Sudan. Bioresour Technol. 2005;96(1):79-85.

34. Khider TO, Elzaki OT, Omer SH. Soda and soda-AQ pulping of Albizia bebbeck from Sudan. Suranaree J Sci Technol. 2011;18(4):299-303.

35. Khider TO, Omer SH, Elzaki OT. Pulping and totally chlorine free (TCF) bleaching of Acacia mellifera from Sudan. World Appl Sci J. 2012;16(9):12561261.

36. Masrol SR, Ibrahim MHI, Adnan S, Talib MR, Sian L. Effect of soda-anthraquinone pulping variables on durian rind pulp and paper characteristics: a preliminary test. In: Materials Science and Engineering. 2017226. Bristol; IOP Publishing.

37. Sarwar Jahan M, Sarkar M, Quaiyyum MA. Pulping of Gamarri root (Gmelina arborea). J Indian Acad Wood Sci. 2018;15(2):1-5. 